\title{
ESTUDO SOBRE O PROFESSOR REFLEXIVO
}

\author{
CORAL, Maurício Abel ${ }^{1}$ \\ MILIOLI, Bruno Beloli ${ }^{2}$ \\ PEREIRA, Viviane Ribeiro ${ }^{3}$ \\ VIEIRA, Erica ${ }^{4}$ \\ MORAES, Diênifer ${ }^{5}$ \\ ORTIGARA, Vidalcir ${ }^{6}$
}

\begin{abstract}
RESUMO
A produção do presente artigo tem como objetivo apresentar alguns debates entre abordagens que defendem a formação de professores a partir de uma perspectiva de reflexão sobre a prática pedagógica e abordagens que criticam e apontam limitações e incapacidades dessa perspectiva de formação reflexiva do professor de alcançar àquilo a que se propõe: a formação de um profissional da educação verdadeiramente crítico e autônomo. Como procedimento metodológico desta pesquisa, utilizamo-nos da pesquisa indireta, bibliográfica e documental, de acordo com Bardin (2004). Para alcançarmos êxito neste trabalho, trouxemos às discussões autores como Schön (1992), Zeichner (1993) e Shulman (1992), considerados os proponentes das principais abordagens reflexivas: narrativa, crítica e cognitivista, respectivamente. Estas abordagens foram discutidas a partir dos estudos de Facci (2004) que, sob uma fundamentação materialista histórico-dialética e histórico-cultural, analisou o percurso histórico das abordagens reflexivas citadas, destacando suas possibilidades e limites. Evidenciamos com este estudo que as abordagens reflexivas narrativa, crítica e cognitivista, que se propõem a formar professores críticos e autônomos, acabam prezando pela valorização do ensino de competências em detrimento da transmissão de conhecimentos teóricos; pela reflexão sobre a prática centrada no indivíduo, perdendo-se a dimensão que o mesmo só se constitui enquanto indivíduo dentro de um contexto social, que o influencia e é influenciado por ele ao mesmo tempo, no mesmo processo dialético.
\end{abstract}

PALAVRAS-CHAVE: Professor reflexivo; Formação Crítica; Reflexão sobre a prática.

\begin{abstract}
The production of this article is to present some debates between approaches that advocate teacher training from a reflective perspective on pedagogical practices and approaches that criticize and point out limitations and disabilities that reflexive education perspective teacher to achieve the to what is proposed: the formation of a professional truly critical education and autonomous. As a methodological procedure of this research, we use the indirect, bibliographic and documentary research, according to Bardin (2004). To achieve success in this work, the authors brought discussions as Schön (1992), Zeichner (1993) and Shulman (1992), considered the main proponents of reflective approaches: narrative, critical and cognitive, respectively. These approaches were discussed from the study Facci (2004) that, in a historical and dialectical materialist foundation and historical-cultural, analyzed the historical course of reflexive approaches mentioned, emphasizing their possibilities and limits. We demonstrated with this study that the reflective narrative approaches, critical and cognitive, which propose to form critical and independent teachers, end up valuing the appreciation of the teaching skills rather than the transmission of theoretical knowledge; by reflection on the practice based on the individual dimension is missing that it is only as an individual within a social context that influences and is influenced by it at the same time in the same dialectical process.
\end{abstract}

\footnotetext{
${ }^{1}$ UNESC - mauricioabelcoral@gmail.com

${ }^{2}$ UNESC - bruno.milioli@gmail.com

${ }^{3}$ UNESC - vivianeribeirop@hotmail.com

${ }^{4}$ UNESC - ericazimba@gmail.com

${ }^{5}$ UNESC - dieny_dlm@hotmail.com

${ }^{6}$ UNESC - vdo@unesc.net
} 
KEYWORDS: Reflective Teacher; Critical training; Reflection on practice.

\section{INTRODUÇÃO}

Desde a passagem do século XX para o século XXI, podemos perceber uma série de problemas decorrentesdas disputas entre as classes que estruturam o modelo social, político e econômico capitalista em que vivemos. A dizer, estas classes possuem objetivos antagônicos: a dominante, capitalista, minoritária numericamente, detentora dos meios de produção, cujo objetivo é a manutenção das relações sociais que estão postas; e a dominada, formada pelos trabalhadores, majoritária numericamente, explorada nas relações de trabalho e cujo objetivo é a superação da sociabilidade atual (MARX, 2013).

Segundo Facci (2004), vivemos em uma época marcada por transformações profundas e contraditórias. O mesmo processo que promoveu grandes avanços tecnológicos responsáveis pelo aumento da produtividade, capazes de liberar o homem do trabalho mecânico e repetitivo, também trouxe consequências perversas, tornando precária a vida de grande parte dos habitantes do mundo, levando o "flagelo do desemprego para milhões de pessoas no mundo contemporâneo" (FACCl, 2004, p. 5). Essa situação acabou por conduzir um número cada vez maior de pessoas a não terem acesso às necessidades humanas mais essenciais, mais básicas de sobrevivência, colocando-as à margem da economia, em condições subumanas.

Neste contexto de modernidade que, para Berman (1986), é um conjunto de experiências de tempo e espaço, de si mesmo e dos outros, das possibilidades e perigos da vida, compartilhada por homens e mulheres em todo o mundo, o termo empregabilidade ganha muita força no discurso ideológico dominante. Conforme Gentili (2002), este é um discurso que parte do pressuposto de que o incremento no capital humano individual aumenta as condições do indivíduo em inserir-se no mercado de trabalho. No entanto, não há garantias que esse indivíduo realmente será absorvido pelo mercado, pois, por mais bem qualificados que os trabalhadores possam estar, nas condições objetivas atuais, não há postos de trabalho disponíveis para todos.

A ênfase na dimensão individual do trabalhador traz consigo outras consequências, como a responsabilização e a culpabilização deste pelo precário panorama das suas 
condições de trabalho, creditando ao mesmo a resolução de todos os seus problemas, sem levar em consideração que o trabalhador é apenas um dos tantos elementos que compõe o mercado de trabalho e as suas relações. Há uma transferência de responsabilidade do aspecto social para o individual na inserção profissional dos indivíduos. Porém essa transferência não aparece declaradamente no discurso dominante, e nem mesmo é perceptível aos trabalhadores de maneira imediata, pois vem sendo naturalizada nas relações sociais ao longo do tempo.

O professor, inserido em meio a esse contexto de transformações, muitas vezes também é visto como o "culpado" pelos problemas existentes no âmbito escolar, por exemplo: fracasso escolar, indisciplina e violência na escola, dificuldades de aprendizagem, entre outros.A empregabilidade também aparece fortemente nas relações do trabalho docente, procurando basear as ações do professor quase que exclusivamente nas suas competências técnicas, ou seja, no seu saber-fazer. De acordo com Facci (2004, p. 33-34)

\begin{abstract}
Não podemos negar que os professores estão enfrentando este mal-estar; no entanto, é necessário entender o processo que vem ocorrendo de desmantelamento da escola e mesmo de uma banalização do conhecimento em prol de uma "sociedade do conhecimento" na qual o objetivo maior é pensar na empregabilidade, em formas de adequar os alunos aos preceitos neoliberais, na qual a competência e a aquisição de habilidades são mais importantes que o conhecimento histórico-científico [...]
\end{abstract}

$\mathrm{Na}$ educação brasileira a relação entre trabalho, empregabilidade e competências ganha destaque com a difusão das ideias de autores que entendem que a educação escolar tem como função precípua ensinar aos alunos as habilidades necessárias à execução da atividade de trabalho, dentro das relações capitalistas de produção.

Talvez, o principal autor deste pensamento seja Philippe Perrenoud (1999). Este autor entende que competência é "uma capacidade de agir eficazmente em um determinado tipo de situação, apoiada em conhecimentos, mas sem limitar-se a eles" (PERRENOUD, 1999, p. 7).

Perrenoud(1999, p. 10), baseando-se na teoria de Piaget, afirma que a construção de competências é 
[...] inseparável da formação de esquemas de mobilização dos conhecimentos com discernimento, em tempo real, ao serviço de uma ação eficaz [...]. Os esquemas constroem-se ao sabor de um treinamento, de experiências renovadas, ao mesmo tempo redundantes e estruturantes, treinamento esse tanto mais eficaz quando associado uma postura reflexiva.

Esta compreensão possibilitou o surgimento de concepções que tratam da formação do professor numa abordagem reflexiva, interesse de nosso estudo, cujo objetivo é apresentar e discutir essas concepções, em contraponto com as contribuições da fundamentação materialista histórico-dialética e da teoria histórico-cultural, o qualpassaremos a discorrer a partir do próximo item.

\section{METODOLOGIA}

Realizamos alguns debates em torno da abordagem reflexiva para a formação de professores, numa dimensão contextualizada, buscando o confronto de seus propositores, dentre os quais se destacam Schön (1992), Zeichner (1993) e Shulmann (1992), com algumas das respectivas críticas realizadas até então, principalmente por Facci (2004), questionando se tal abordagem possibilita a efetivação daquilo a que se propõe: uma formaçãode docentes críticos e autônomos.

Nesse movimento, apresentamos as diferentes correntes dentro da abordagem reflexiva que encontramos em nossas pesquisas; também apresentamos algumas críticas a essa abordagem; além de uma síntese das considerações que nos foi possível elaborar ao longo desse processo de pesquisa.

Para entendermos mais sobre essa temática, utilizamos como procedimento metodológico o formato de pesquisa indireta e bibliográfica, orientados pela análise de conteúdo proposta por Bardin (2004), que nos guiaram, principalmente, por meio de seu procedimento prático.

\section{O PROFESSOR REFLEXIVO}

A formação do professor, numa abordagem do ensino reflexivo, teve início na Inglaterra, na década de 1960, e nos EUA, nos anos de 1980. Conforme Facci (2004), 
este conceito de professor reflexivo emergiu, inicialmente, como reação à concepção tecnocrática do professor que enfatizava a aprendizagem de técnicas, o racionalismo técnico. Racionalismo técnico entendido, aqui, como a transmissão pelo professor de conhecimentos prontos e acabados, que poderiam ser aplicados de forma direta na resolução de problemas sem a preocupação com o contexto, evidenciando uma dimensão instrumental da atividade do professor.

Dessa maneira a formação do professor sob uma perspectiva de ensino reflexivo, traria um avanço em relação à concepção racionalista tecnicista de ensino, encarando o docente como um intelectual em contínuo processo de formação, tendo a experiência como fonte do saber e, através dela, a construção do seu saber profissional.

Entretantoainda não existe um significado exato, um consenso entre os pesquisadores da formação de professores a respeito do conceito de professor reflexivo. Facci (2004),propõeque sejam consideradas três abordagens sobre a formação reflexiva dos professores: a narrativa, a crítica e a cognitivista; ressaltando que estas não são excludentes entre si.

\section{Abordagem Narrativa}

Na década de 1980 as ideias de Donald Schön começaram a ser difundidas e provocaram algumas considerações sobre a abordagem reflexiva na formação de professores. Posteriormente conhecidas pelo que é considerado, hoje, o professor prático-reflexivo.

De acordo comSchön(1992), a educação deve ser ativa e estar relacionada com os interesses da criança, sendo que cabe ao professor aconselhar, orientar e conduzir a atividade do aluno em direção ao saber. O professor, nessa perspectiva, deve incentivar o aluno a examinar mentalmente as questões postas,partindo de suas experiências próprias em direção ao pensamento reflexivo.

Para o autor, algumas noções são consideradas fundamentais na constituição do processo de reflexão. A primeira noção caracteriza-se pelos conhecimentos que os profissionais demonstram na execução da ação, conhecimento-naação. A segunda, aponta que o pensamento reflexivo se constitui no processo de 
reflexão-na-ação, ou seja, o profissional pensa sobre o que faz ao mesmo tempo em que está atuando. Já a terceira refere-se à reflexão-sobre-a-ação, em que o professor faz uma reflexão crítica depois de realizada a ação. E, a última, diz respeito à reflexão-sobre-areflexão-na-ação, na qual o professor faz uma reflexão crítica sobre a crítica da ação realizada.

Assim, a proposta de formação de professores, nessa perspectiva (professor prático-reflexivo), salienta o aspecto da prática como fonte de conhecimento por meio da reflexão e da experimentação. A tarefa do formador consiste primordialmente em facilitar a aprendizagem, em ajudar a aprender (FACCI, 2004).

\section{Abordagem Crítica}

Esta abordagem tem em Kenneth Zeichner seu principal expoente. Este autor aponta alguns limites da teoria de Schön (1992), pois- apesar de se contrapor à racionalidade técnica e colocar a reflexão como parte do processo de trabalho educacional, esta teoria está embasada em pressupostos de profissionais que realizam, individualmente, práticas reflexivas de forma reducionista, por isso buscam alterar apenas suas práticas. Constatando isso, Zeichner (1993) amplia o conceito de prático reflexivo, afirmando ser necessário levar a ação reflexiva para além dos muros da escola.

Com isto, Zeicnher(1993) não afirma que Schön (1992)deixa de levar em consideração as questões institucionais, mas que sua teoria não proporciona uma análise que ajude a entender se esta reflexão questiona ${ }_{-}$ou não, os limites das compreensões dos profissionais que realizam este processo de reflexão.

Para Zeichner (1993) nos estudos sobre o ensino reflexivo na formação de professores, uma das características mais marcantes é a sua natureza a-histórica. É de suma importância o estudo das tradições da prática na formação de professores. Nesse sentido, o mesmo autor identificou cinco concepções que embasam os cursos de formação de professores:

- $\quad$ aacadêmica, na qual o importante é ensinar conteúdos curriculares e os professores são encarados como acadêmicos e especialistas das matérias de estudo; 
- $\quad$ aeficiência social, que é desenvolvida com base nas competências e no desempenho (eficiência/behaviorismo) e alicerça a formação em dados resultantes das investigações sobre $o$ ato de ensinar;

- adesenvolvimentista, cuja ênfase está nos processos de desenvolvimento e aprendizagem, relacionada a teorias construtivistas;

- $\quad$ areconstrução social, que enfoca a necessidade de um reflexão crítica que se centre na análise das condições éticas e políticas da escola;

- a genérica, na qual há a defesa do ensino reflexivo, sem ênfase sobre qual deve ser o tema de reflexão.

Conforme sinaliza Facci (2004), diferentemente de Schön (1992), que trata de um professor prático-reflexivo, Zeichner (1993) entende o professor como investigador, utilizando a pesquisa-ação em seus programas de formação de professores. Nesta proposta de pesquisa-ação, o conhecimento não é considerado exclusividade de pesquisadores ou acadêmicos, pois os sujeitos a serem pesquisados possuem conhecimentos que também devem ser valorizadospara a qualificação da pesquisa

\section{Abordagem Cognitivista}

A perspectiva cognitivista de Shulman (1992) também está dentro da abordagem do professor reflexivo. Este autor é um estudioso dos diferentes tipos de modalidades de conhecimento que os professores dominam. De acordo com Shulman (1992), os professores precisam ter três tipos de conhecimento: conteúdo, pedagógico do conteúdo e curricular.

O primeiro tipo é o conhecimento do conteúdo específico, próprio da matéria a ser ensinada. O segundo tipo está mais relacionado à capacidade de ensinar, vai além do conteúdo específico, e ainda implica analogia, exemplificação, demonstração, para que os alunos tenham uma melhor compreensão. O terceiro tipo, curricular, compreende a estruturação e a organização de conhecimentos escolares e seus respectivos materiais (vídeos, jogos pedagógicos etc.).

De acordo com Facci (2004), os conhecimentos apresentados por Shulman (1992)aparecem de três formas:

Criar Educação, Criciúma, v. 6, ํำ1, janeiro/junho 2017.- PPGE - UNESC 
- conhecimentoproposicional: relativo à investigação didática, ocorre pela apresentação de fatos, princípios e máximas. Geralmente não está relacionado às experiências e vivências dos alunos;

- conhecimentode caso: refere-se a eventos específicos, composto de exemplos ricamente descritos que auxiliam a compreensão da teoria;

- conhecimentoestratégico: que se manifesta em situações práticas da sala de aula, envolvendo formas de agir em situações contraditórias.

Após apresentarmos as diferentes abordagens relacionadas ao professor reflexivo encontradas em nossas pesquisas, buscamos verificar, também, quais críticas são apontadas por pesquisadores da área da educação que discorrem sobre esse assunto. Diante disso, trouxemos as considerações desses autores sobre a temática do professor reflexivo na formação docente.

\title{
CRÍTICAS ACERCA DO PROFESSOR REFLEXIVO
}

No que tange às discussões sobre competências,Pimenta(2012) ressalta que esse conceito está "substituindo o de saberes e conhecimentos (no caso da educação) e o de qualificação (no caso do trabalho)", afirmando que não se trata de mera questão conceitual. Essa substituição acarreta consequências para os professores, "uma vez que os expropria de sua condição de sujeito do seu conhecimento" (PIMENTA, 2012, p. 49).

A autoracontinua sua análise afirmando que

\begin{abstract}
Nesse sentido, o discurso das competências poderia estar anunciando um novo (neo)tecnicismo, entendido como um aperfeiçoamento do positivismo (controle/avaliação) e, portanto, do capitalismo. [...] O termo competência, polissêmico, aberto a várias interpretações, fluido, é mais adequado do que o de saberes/qualificação para uma desvalorização profissional dos trabalhadores em geral e dos professores. Competências, no lugar de saberes profissionais, deslocam do trabalhador para o local de trabalho a sua identidade, ficando este vulnerável à avaliação e controle de suas competências, definidas pelo "posto de trabalho" (PIMENTA, 2012, p. 49).
\end{abstract}

Pimenta (2012, p. 50) indica, também,a importante diferenciação que há entre a compreensão de competência e de conhecimento: 
Mas ter competência é diferente de ter conhecimento e informação sobre o trabalho, sobre aquilo que se faz (visão de totalidade; consciência ampla das raízes, dos desdobramentos e implicações do que se faz para além da situação; das origens; dos porquês e dos para quê). Portanto, competência pode significar ação imediata, refinamento do individual e ausência do político, diferentemente da valorização do conhecimento em situação, a partir do qual o professor constrói conhecimento. $\mathrm{O}$ que só é possível se, partindo de conhecimentos e saberes anteriores, tomar as práticas (as suas e as das escolas), coletivamente consideradas e contextualizadas, como objeto de análise, problematizando-as em confronto com o que sabe sobre elas e em confronto com os resultados sociais que delas se esperam. Os saberes são mais amplos, permitindo que se critiquem, avaliem e superem as competências.

A valorização do conhecimento na formação do professor em contrapartida ao seu rebaixamento e limitação, quando centralizada nas competências necessárias à pratica docente, também é discutida por Moraes (2009). A autora relaciona a questão das competências aos interesses das diferentes classes sociais, afirmando que há um claro discurso no qual é preciso que os professores assegurem o desenvolvimento de competências, além de educar. Porém as competências não seriam as mesmas para todos.

\begin{abstract}
Para alguns, exige níveis sempre mais altos de aprendizagem, posto que certas "competências" repousam no domínio teórico-metodológico que a experiência empírica, por si só, é incapaz de garantir. Para a maioria, porém, bastam as "competências", no sentido genérico que o termo adquiriu hoje em dia, o de saber tácito, que permitem a sobrevivência nas franjas do núcleo duro de um mercado de trabalho fragmentado, com exigências cada vez mais sofisticadas e formidáveis níveis de exclusão. Tal determinação da educação associa-se à necessidade do capital de contar com uma força de trabalho em espera (exército industrial) adaptável às novas exigências da reprodução. $E$, claro, transferindo todo ônus dessa formação para a classe trabalhadora (MORAES, 2009, p. 319-320).
\end{abstract}

Sobre a abordagem narrativa, cujo principal expoente é Donald Schön, conhecida como a teoria do professor prático-reflexivo, Facci (2004) destaca que esta demonstra avanços com relação ao racionalismo técnico, porém ainda não proporciona uma análise que ajude a entender se a reflexão (no sentido que o termo possui para esta teoria) questiona os limites das compreensões que fazem os profissionais ao realizarem-na. Fazse necessário, portanto, uma vinculação com as considerações sociais, políticas e econômicas quando se trata de compreender a formação e a prática pedagógica dos professores. 


\section{CRIAR EDUCAÇÃO \\ Revista do Programa de Pós-Graduação em Educação - UNESC \\ unesc \\ PPG

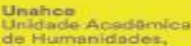

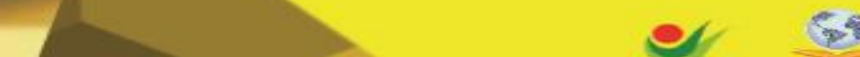

Serrão (2012) compreende que a perspectiva do professor reflexivo possui limites que a própria forma de organização capitalista da sociedade impõe aos educadores. A autora questiona as posições de Schönenfatizando que há aspectos que configuram o trabalho do professor que são de ordem institucional e política, que não dependem exclusivamente de uma atitude reflexiva e crítica que tenha, por si só, condições de romper com uma prática profissional envolvida pela trama social complexa e contraditória.

Acerca da abordagem crítica de Zeichner,Facci (2004, p. 54) afirma que:

O que se pode perceber é que a abordagem de Zeichner é apresentada como se fosse uma abordagem crítica por considerar a reflexão coletiva e contemplar a dimensão política. No entanto, parece-me que a dimensão política desse pesquisador está ancorada em ideários propostos pela burguesia, fundamentando-se nos princípios de "igualdade", "justiça social", "fraternidade", "liberdade", palavras de ordem que cumprem a função de mostrar o humanismo possível dentro do capitalismo, o que se constitui num grande engodo.

A autora complementa:

Além do mais, do meu ponto de vista, refletir coletivamente não significa que esta reflexão esteja pautada em argumentos que levem em consideração o contexto sócio-histórico no qual o professor desenvolve sua prática, ou mesmo que se analisem as relações que perpassam os pesquisadores e os professores. Não é suficiente apenas dar "voz aos professores", é preciso que eles reflitam em que condições econômicas, políticas e sociais desenvolvem a profissão e que necessidades postas pelo capital exigem dos professores esta ou aquela postura-(FACCl, 2004, p. 54).

$\mathrm{O}$ que tem acontecido com o conceito de professor reflexivosegundo Pimenta(2012, p. 27), é um "oferecimento de treinamento para que o professor torne-se reflexivo". O entendimento que se tem da reflexão, segundo essa autora, é que esta se constitui como uma forma de superação dos problemas cotidianos vivificados pelos professores na prática pedagógica. Essa massificação do termo distancia o profissional de uma reflexão no sentido marxista, dificultando o engajamento dos docentes em práticas mais críticas, reduzindo-o a um fazer técnico, a um mero pragmatismo.

Para a autora, a apropriação generalizada da perspectiva da reflexão, inclusive nas reformas educacionais no Brasil, transforma o conceito de professor reflexivo apenas em uma expressão da "moda", uma vez que o despe de sua potencial dimensão político- 
epistemológica, pois não se transforma em medidas para a efetiva elevação do estatuto da profissão professor e para a melhoria das condições escolares.

Arce (2001), comenta que a formação do professor necessita estar embasada em fundamentos filosóficos, políticos, sociais, históricos, assim como em sólida formação didático-metodológica,

visando formar um profissional capaz de teorizar sobre as relações entre educação e sociedade e, aí sim, como parte dessa análise teórica, refletir sobre a sua prática, propor mudanças significativas na educação e contribuir para que os alunos tenham acesso à cultura resultante do processo de acumulação sóciohistórica pelo qual a humanidade tem passado (ARCE, 2001, p. 267).

Facci (2004) subscreve a relevância da teoria, defendendo que o conhecimento teórico-crítico, já produzido pelas gerações anteriores e que explica a forma histórica de ser dos homens, serve de ferramenta para o correto entendimento e a significação das práticas atuais.

Pimenta(2012) acrescenta, ainda, que o saber docente não é formado apenas pela prática, pois ele deve utilizar o aporte das teorias da educação. Segundoa autora, a teoria tem importância fundamental na formação dos professores, pois proporciona a eles possibilidades de compreender os contextos históricos, sociais, culturais, organizacionais e também aqueles nos quais se inserem como profissionais da educação.

Assim, a teoria como cultura objetivada é importante na formação docente, uma vez que, além de seu poder formativo, dota os sujeitos de pontos de vista variados para uma ação contextualizada. Os saberes teóricos propositivos se articulam, pois, aos saberes da prática, ao mesmo tempo ressignificando-os e sendo por eles ressignificados. O papel da teoria é oferecer aos professores perspectivas de análise para compreenderem os contextos históricos, sociais, culturais, organizacionais e de si mesmos como profissionais, nos quais se dá a sua atividade docente, para neles intervir, transformando-os. Daí, é fundamental o permanente exercício da crítica das condições materiais nas quais o ensino ocorre e de como nessas mesmas condições são produzidos os fatores de negação da aprendizagem $=$ (PIMENTA, 2012, p. 31) 
Consideramos que há limites na compreensão e aplicabilidade das abordagens reflexivas quando se propõem a ser críticas e transformadoras. Diante disso, buscamos caminhos que nos possam possibilitar uma formação e um ensino realmente críticos.

\section{CONSIDERAÇÕES FINAIS}

Diante da realidade, das nossas vivências pessoais e profissionais, de nossos estudos e pesquisas, da nossa capacidade de compreensão das estruturas e mecanismos generativos das objetivações concretas, é visível que há em nossa sociedade uma clara desvalorização do contexto escolar e, consequentemente, do trabalho do professor nos seus diferentes níveis de atuação. Não há interesse por parte da classe dominante burguesa em possibilitar a socialização do saber que desvele as contradições sociais, pois não é desejável que os sujeitos dominados (classe trabalhadora) tenham consciência de sua condição social exploratória.

Quando alguns teóricos defendem o ensino reflexivo, supondo uma formação mais crítica e autônoma, devemos ter muita cautela, pois, durante nossas pesquisas, não nos ficou claro em que momento na formação dos professores em uma perspectiva reflexiva, há a apropriação dos conhecimentos teóricos mais desenvolvidos pelos homens e nem quais seriam estes conhecimentos que orientarão a sua prática. Pareceu-nos que há um movimento de substituição da transmissão de conhecimentos pelo desenvolvimento de competências, o que pouco contribui para a formação profissionais comprometidos com a crítica ao modelo de vida capitalista dominante. Nas abordagens reflexivas, a função do professor parece estar mais no sentido de ajudar os alunos a construírem o conhecimento do que lhes transmitir o saber.

Outro ponto a ser considerado, e que Facci (2004) nos ajuda a compreender, é o fato de que as teorias que ressaltam o trabalho do professor no processo educativo, valorizando suas experiências e a reflexão sobre a prática, correm o risco de apenas analisar a subjetividade do professor, como se esta fosse produzida na particularidade, ou mesmo somente entre seus pares, desconectada da realidade social. Entretanto, precisamos entender que a constituição da subjetividade se dá nas condições históricosociais nas quais o sujeito se desenvolve. 


\section{CRIAR EDUCAĈ̃̃}

Entendemos que,na busca de uma educação realmente crítica, o professor deve apropriar-se dos conhecimentos que ultrapassam o senso comum, dos conhecimentos produzidos e acumulados pelos homens, para que possibilite aos seus alunos não apenas o acesso a eles, mas também como se situarem e se compreenderem criticamente dentro do processo social contemporâneo.

\section{REFERÊNCIAS}

ARCE, Alessandra. Compre o kit neoliberal para a educação infantil e ganhe grátis os dez passos para se tornar um professor reflexivo. Educação \& Sociedade. Campinas, ano XXII, n. 74, p. 251-283, abr. 2001. Disponível em: http://www.scielo.br/pdf/es/v22n74/a14v2274.pdf. Acesso em: 11 set. 2013.

BARDIN, Laurence. Análise de conteúdo. 3. ed. Lisboa: Edições 70, 2004.

BERMAN, Marshall. Tudo que é sólido desmancha no ar: A aventura da modernidade. São Paulo: Companhia das Letras, 1986.

FACCI, Marilda Gonçalves Dias. Valorização ou esvaziamento do trabalho do professor?: um estudo crítico-comparativo da teoria do professor reflexivo, do construtivismo e da psicologia vigotskiana. Campinas, SP: Autores Associados, 2004.

GENTILI, Pablo. Três teses sobre a relação trabalho e educação em tempos neoliberais.In: LOMBARDI, José Claudinei; SAVIANI, Dermeval; SANFELICE, José Luis (Orgs.). Capitalismo, trabalho e educação. Campinas, SP: Autores Associados, 2002. p. 45-61.

MARTINS, Lígia Márcia. Da formação humana em Marx à crítica da pedagogia das competências. In: DUARTE, Newton (Org.). Crítica ao fetichismo da individualidade. Campinas, SP: Autores Associados, 2004. p. 53-73.

MARX, Karl. O capital: crítica da economia política. São Paulo: Boitempo, 2013.

MORAES, Maria Célia Marcondes de. Indagações sobre o conhecimento no campo da educação. Perspectiva, Florianópolis, v. 27, n. 2, p. 315-346, jul./dez. 2009. Disponível em: $\quad$ http://www.perspectiva.ufsc.br/perspectiva 2009 02/PDFs 27 2/MariaCelia.pdf. Acesso em: 15 set. 2013.

PERRENOUD, Philippe. Construir as competências desde a escola. Porto Alegre: Artes Médicas Sul, 1999.

PIMENTA, Selma Garrido. Professor reflexivo: construindo uma crítica. In: PIMENTA, Selma Garrido; GHEDIN, Evandro (Orgs.). Professor reflexivo no Brasil: gênese e crítica de um conceito. 7. ‥ ed. São Paulo: Cortez, 2012. 
SERRÃO, Maria Isabel Batista. Superando a racionalidade técnica na formação: sonho de uma noite de verão. In: PIMENTA, Selma Garrido; GHEDIN, Evandro (Orgs.). Professor reflexivo no Brasil: gênese e crítica de um conceito. 7. $\underline{\underline{a}}$ ed. São Paulo: Cortez, 2012. p. 174-184.

SCHÖN, Donald. Formar professores como profissionais reflexivos. In. NÓVOA, Antônio. Os professores e a sua formação. Lisboa: D. Quixote, 1992. p. 79-91.

SHULMAN, Lee. Reviewing the pedagogy of teacher education the impact of subjectspecifc conceptions of teaching. In: MONTERO MESA, L.; JEREMIAS VAZ, J. M. LasDidácticas Especificas enlaFormacióndelProfesorado. Santiago de Compostela: TórculoEdicións, 1992.

ZEICHNER, Kenneth M. A formação reflexiva de professores: ideias e práticas. Lisboa: Educa, 1993. Disponível em: <http://repositorio.ul.pt/handle/10451/3704>. Acesso em: 11 set. 2013. 